\title{
Recovery of marine animal populations and ecosystems
}

\author{
Heike K. Lotze ${ }^{1}$, Marta ColI ${ }^{1,2}$, Anna M. Magera ${ }^{1}$, Christine Ward-Paige ${ }^{1}$ and \\ Laura Airoldi ${ }^{3}$
}

\author{
${ }^{1}$ Biology Department, Dalhousie University, Halifax, Nova Scotia, B3H 4R2, Canada \\ ${ }^{2}$ Institut de Ciències del Mar (ICM-CSIC), Passeig marítim de la Barceloneta, n 37-49, 08003, Barcelona, Spain \\ ${ }^{3}$ Dipartimento di Biologia Evoluzionistica Sperimentale and CIRSA, Università di Bologna, Via S. Alberto 163, 48123 Ravenna, Italy
}

\begin{abstract}
Many marine populations and ecosystems have experienced strong historical depletions, yet reports of recoveries are increasing. Here, we review the growing research on marine recoveries to reveal how common recovery is, its magnitude, timescale and major drivers. Overall, $10-50 \%$ of depleted populations and ecosystems show some recovery, but rarely to former levels of abundance. In addition, recovery can take many decades for long-lived species and complex ecosystems. Major drivers of recovery include the reduction of human impacts, especially exploitation, habitat loss and pollution, combined with favorable life-history and environmental conditions. Awareness, legal protection and enforcement of management plans are also crucial. Learning from historical recovery successes and failures is essential for implementing realistic conservation goals and promising management strategies.
\end{abstract}

\section{A new focus on recovery}

An increasing number of studies have reported strong declines in marine animal populations and the degradation of ocean ecosystems over past decades and centuries around the world [1-7], leading to a widespread perception of empty oceans and polluted waters. Yet, throughout history, humans have responded to declining resource abundance and ecosystem degradation by implementing management and conservation measures. Some of these have been successful and resulted in recovery, whereas others have failed $[3,8,9]$.

Therefore, an important question to science and management is: how common is recovery among depleted populations and degraded ecosystems in the ocean? Today, many marine mammal, bird, reptile and fish populations are at low abundance, and several species are endangered or extinct on regional or global scales [5,10-12]. However, despite long periods of intense human impacts, most marine species persist and some populations do show signs of recovery $[3,8,9]$. Similarly, many coastal habitats, including wetlands, seagrass beds, mangrove and kelp forests, and oyster and coral reefs, have been severely reduced or degraded [2-4,6], yet partial recovery has been achieved in some regions in response to protection and pollution controls $[3,13]$. Restoration attempts at an ecosystem level have often been followed by the return and recovery of

Corresponding author: Lotze, H.K. (hlotze@dal.ca). former species assemblages and ecosystem functions [13-17], but some ecosystems have remained in an altered state [18]. Such successes could serve as important guides for efforts to prevent further biodiversity loss and enhance future recoveries.

Despite a growing number of case studies on the recovery of specific populations or ecosystems, an overview of the general patterns and drivers of marine recoveries over historical timescales is lacking. A recent review on the recovery of damaged ecosystems found that many terrestrial and marine ecosystems can recover on timescales of a few years to a few decades after major perturbations [19]. However, most case studies in the review, especially among marine and brackish examples, included small, short-lived organisms, such as microbes, algae and invertebrates, which have much higher recovery potential compared with long-lived marine vertebrates. Moreover, the review largely dealt with recovery from shorter-term impacts, such as eutrophication and oil spills, rather than long-term impacts, such as exploitation or habitat loss. Other studies showed that recovery often depends on intrinsic factors, such as life-history characteristics and genetic diversity [20], extrinsic factors, such as the type and magnitude of disturbance [21-23], and the conservation and management measures applied to reduce human impacts $[3,8,9]$. Thus, a broader and more nuanced treatment of marine recovery patterns and drivers is warranted.

Over the past decade, there have been significant advances in understanding recoveries in the ocean. Here, we review and summarize the patterns and drivers of welldocumented recoveries in marine populations and ecosystems, with a focus on long-lived mammals, birds, reptiles, fishes and habitats depleted by a long history of human impacts. Our aim is to derive general answers to the questions of how common recovery is among depleted populations and degraded ecosystems, what the magnitude of recovery is and how long it takes. We also provide an overview of the main factors that enabled recovery, including management, conservation and legal actions, shifts in cultural or economic values, and population and ecosystem characteristics. We highlight important lessons and gaps for future research, and discuss how emerging knowledge on marine recoveries can be used to develop successful strategies and targets for current conservation and management. 


\section{What is recovery?}

Although interest in marine recoveries is increasing, there is no standard definition of recovery [24]. It can mean many things depending on who is measuring it (e.g. scientist, governmental or non-governmental organization, or industry), what is measured (e.g. population or ecosystem parameters, or fisheries catches) or the goals involved (e.g. conservation or management targets, or revenue). Recovery is defined as 'a return to a normal state of health, mind, or strength' (http://oxforddictionaries.com/), but such a 'normal state' is often not known for marine populations and ecosystems owing to a long history of humaninduced changes and shifting baselines [1-5] as well as different, and sometimes controversial, methodologies used to reconstruct historical reference points [4,5,25]. In addition, natural fluctuations in populations and ecosystems can mask or alter human-induced changes. Sometimes, these can be teased apart [26,27], but in other cases they are confounded or act in combination $[5,27,28]$. Nevertheless, increasing understanding of the natural dynamics of ecological systems and their past histories of change can help to identify meaningful reference points that might assist in assessing recovery.

In theory, in the face of external natural or anthropogenic disturbances, populations or ecosystems can be resistant and remain fundamentally unchanged, or they can be damaged (depleted or degraded) and: (i) fully recover to their initial state after the disturbance; (ii) partially recover to a reduced, altered or alternative stable state; or (iii) irreversibly remain in a damaged state for a long time (Figure 1a). Resistance, recovery and reversibility are important features of the resilience of populations and ecosystems in the face of disturbance [29-31]. However, distinguishing reversible changes from alternative stable states or phase shifts is not easy and might hamper recovery efforts [24].

In practice, recovery is often measured as some form of increase, improvement or shift in certain response variables, ideally reversing to pre-disturbance conditions (Box
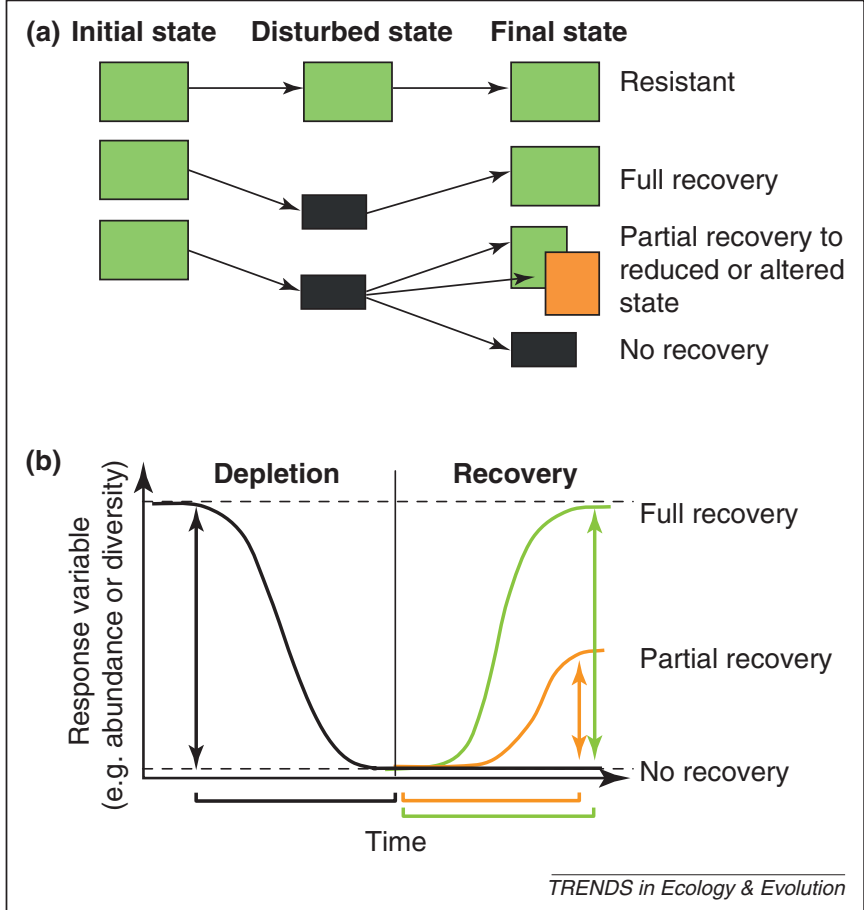

Figure 1. Illustration of theoretical and practical aspects of recovery. (a) In the face of external disturbances, populations or ecosystems can be resistant and remain fundamentally unchanged (green boxes) or they can be disturbed (depleted or degraded; dark-gray boxes) and, afterwards, either fully recover to their initial state, partially recover to a reduced or altered state (orange box), or irreversibly remain in the disturbed state. (b) Recovery can be measured as the magnitude (arrows), rate (slope) and time of increase (or sometimes decrease) in a response variable, and compared to the magnitude, rate or time of previous depletion or degradation. Note that 'no recovery' could also consist of further decline or degradation.

1). For populations, the response is often measured as their abundance, distribution, size structure or functional role; for ecosystems, the response can involve structural parameters, such as species diversity, habitat availability, foodweb composition or water quality, or functional characteristics, such as productivity or nutrient cycling [3,19,32].

\section{Box 1. Definitions of recovery}

Recovery of populations (e.g. in terms of abundance, distribution, size or age structure, or functional role) or ecosystems (e.g. in terms of diversity, habitat availability, food-web structure or water quality) can be defined and measured in different ways, as detailed below. Simple increase

A simple increase is a general increase or improvement in the specified response over time, ideally a reversal towards pre-disturbance conditions. This can be measured as a relative or absolute change since a disturbed state or other reference point (see below). The trend can be linear, exponential or otherwise increasing or, for some parameters, decreasing (e.g. pollution levels). The trend could also be measured over a certain time period, such as the past 10 or 50 years, or since the implementation of an important management measure [20].

Standardized or scaled increase

If the purpose is to compare across different species or ecosystems, the measured improvement would ideally be scaled to, or standardized by the life histories of the species involved (e.g. generation time or intrinsic growth rate, $r_{\max }$ ) or rates of succession of different ecosystems to account for underlying differences in the timescale of responses [12] (Anna M. Magera, MSc thesis, Dalhousie University, 2011).

Increase towards a specified target

Many conservation or management plans define distinct targets for population abundance or ecosystem parameters, for example the biomass at maximum sustainable yield ( $B_{M S Y}$ ) for assessed fish stocks [8], an optimum sustainable population level (OSP) for marine mammals [89] or the maximum population size observed [90].

Increase to a historical or pristine level

Sometimes, the goal might be to recover a population or ecosystem to its 'natural' state before human disturbance. This requires the knowledge of its historical population level or ecosystem state (i.e. historical baseline) or an understanding of its carrying capacity $(\mathrm{K})$ either under current or historical ecosystem conditions $[3,25]$. Establishing such historical baselines is not easy and can be controversial if different data sources or reconstruction methods reveal different results $[5,25]$. The goal could also be to recover a population to some proportion of its former level or carrying capacity (e.g. $50 \% \mathrm{~K}$ ) or its pre-exploitation or virgin abundance $\left(\mathrm{B}_{0}\right)$.

Recovery of former structure or function

Under some circumstances, the recovery goal might not be an increase in certain parameters but a shift among different demographic, social or functional components within a population (e.g. juvenile:adult or male:female ratios) [91] or ecosystem (e.g. trophic levels, functional groups or habitat composition) $[3,39]$ to restore a former, more robust natural or pristine structure. 


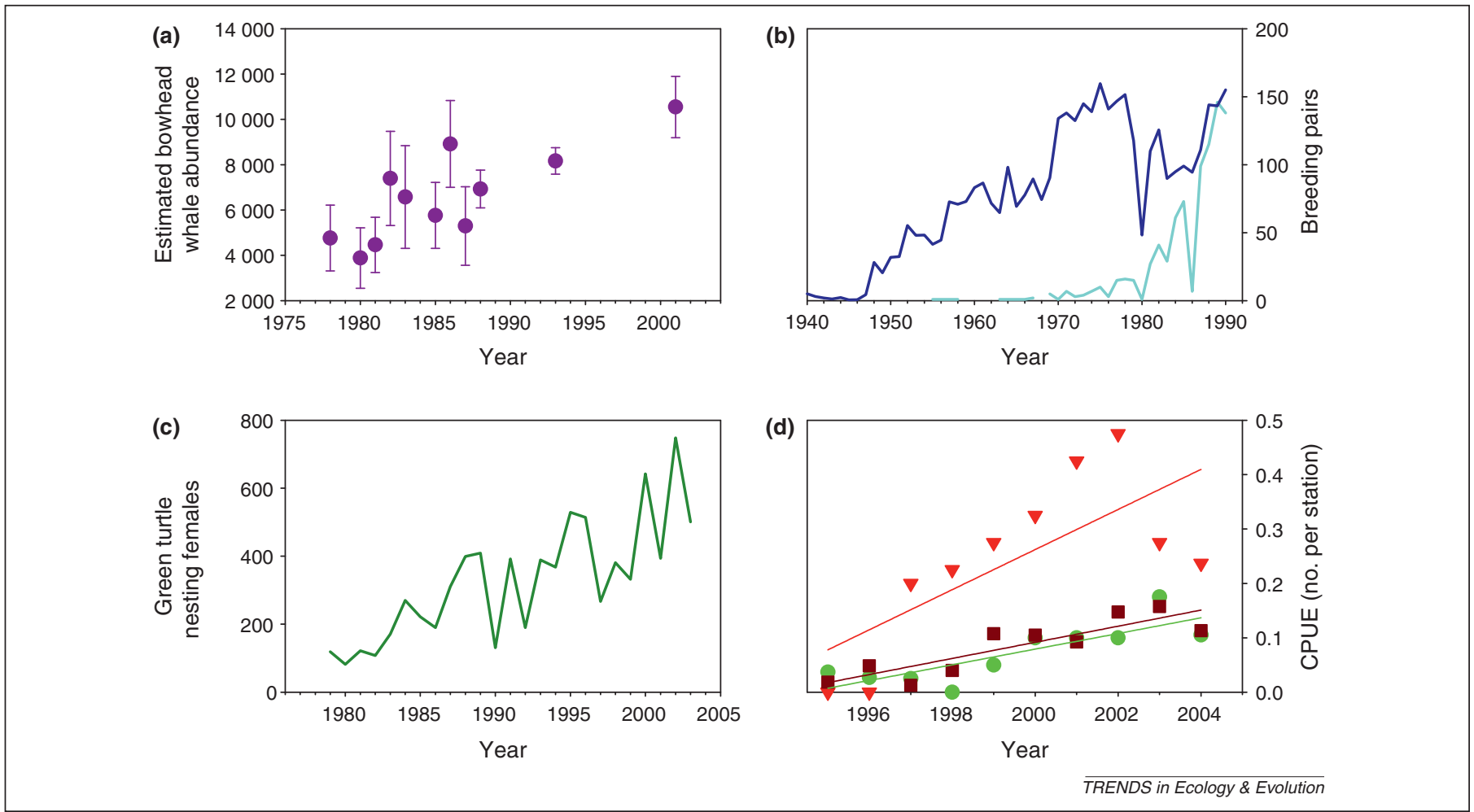

Figure 2. Selected examples of population recovery: (a) Estimated abundance and standard deviation for the western Arctic bowhead whale stock. (b) Breeding pairs of recovering shelducks Tadorna tadorna (dark-blue line) and recolonized common eiders Somateria mollissima (light-blue line) in Niedersachsen, German Wadden Sea. (c) Abundance of green turtle nesting females since 1979 at the Ogasawara rookery on Chichi-jima, Japan. (d) Catch per unit effort (CPUE; and linear regression lines) of giant

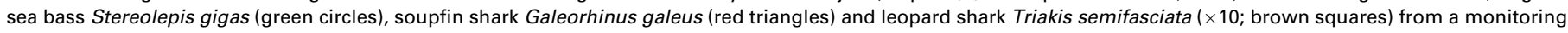
program after the ban of gill nets in 1994 in the Southern California Bight. Reproduced, with permission, from [34] (a), [43] (b), [45] (c) and [48] (d).

The response variables can be analyzed over time to estimate the magnitude, rate and time span of change from a disturbed state or low point (Figure 1b). To place recovery into context, it can be useful to relate these measures to the magnitude, rate and time span of former depletion or degradation, or to scale them to an expected rate of response, such as population growth rate, generation time or succession rate (Box 1). In addition, they should be viewed in the context of natural population fluctuations that can enhance or dampen recovery. Clearly stating which measure is used will enable further comparisons and syntheses across species and ecosystems.

\section{Examples of population and ecosystem recovery}

Over the past decades, an increasing number of studies have reported recoveries of depleted marine populations and degraded ecosystems. We first provide a selection of examples and then synthesize the general patterns.

\section{Marine mammals}

After the League of Nations banned the commercial whaling of strongly decimated right, bowhead and gray whales during the $1930 \mathrm{~s}$, some populations started to recover [e.g. Southern right whales Eubalaena australis, Western Arctic bowhead whales Balaena mysticetus (Figure 2a) and Northeast Pacific gray whales Eschrichtius robustus], whereas others remained at low population levels [25,33,34]. In 1986, the International Whaling Commission expanded the commercial whaling moratorium to all great whales, leading to increases in other species, such as sperm Physeter macrocephalus [35] and blue whales Balaenoptera musculus [36]. Similarly, several populations of pinnipeds and other marine mammals started to increase after the hunting for fur, skin, blubber, ivory or bounty was either prohibited or reduced [3] (Anna M. Magera, MSc thesis, Dalhousie University, 2011). Some populations showed remarkable population increases after being almost extirpated, such as Northern elephant seals Mirounga angustirostris [37] and sea otters Enhydra lutris (Box 2) [38,39].

\section{Birds}

Conservation efforts for birds began during the early 20th century, after a long history of exploitation for their meat, eggs, feathers and oil left many species at very low abundance [3]. The near extinction of the great blue heron Ardea herodias was prevented in the USA by the Federal Lacey Act in 1900, which prohibited the trade of highly valued feathers [40]. The Migratory Bird Treaty Act between the USA and Great Britain in 1918 protected a range of migratory birds from hunting, egg collection and nest destruction [40]. Over time, many countries implemented similar conventions to protect birds and their habitats, enabling many decimated populations to increase (Figure 2b) [41-43], albeit rarely to historical levels [3]. Some species naturally recolonized abandoned breeding colonies or habitats from which they had been extirpated $[42,43]$, whereas others needed assisted re-introduction [42] or formed new colonies at suitable sites [41]. In some cases, eradication of rats, foxes, raccoons or other humanintroduced predators was necessary to restore seabird colonies [42,44]. Another important factor in the recovery of many birds was the ban of DDT during the 1970s [40]. 


\section{Box 2. Case study: recovery of sea otter populations and their kelp habitat}

In the North Pacific, sea otters Enhydra lutris have been heavily exploited for their fur since 1741 [92]. By the end of the 19th century, they were extirpated from much of their historic range, with only approximately 1000 individuals surviving in 13 remnant colonies [92]. First protection from hunting was granted under the International Fur Seal Treaty in 1911. Since then, many populations have increased and natural expansion and human-assisted translocations have aided in recolonizing much of the historic range of the sea otter. However, conservation strategies and recovery trajectories have differed among regions.

In California, sea otters were almost extirpated, but a small group of 50-100 survivors was discovered in 1914 near Point Sur $[40,70]$. Protected under the Fur Seal Treaty, the population started to increase and slowly expanded its range north and south, reaching $>2000$ individuals during the 1990s. Sea otters were further protected under the US Marine Mammal Protection Act (MMPA) in 1972 and listed as threatened in 1977 under the Endangered Species Act (ESA). They thrived especially in marine reserves with abundant food and no hunting, such as in Monterey Bay [70]. Since the mid-1990s, population growth has ceased owing to incidental entanglement and drowning in fishing gear, as well as to disease $[40,93]$.
In British Columbia, sea otters became extirpated in 1929 as a result of the fur trade and continued poaching [38]. Between 1969 and 1972, 89 individuals were translocated in small groups from Alaska into Checleset Bay, Vancouver Island, which was designated as an ecological reserve in 1981. The re-introduction was successful; the population increased to $>3000$ individuals and repopulated $25-33 \%$ of its former range [38]. Originally listed as endangered in 1978 by the Committee on the Status of Endangered Wildlife in Canada (COSEWIC; http://www.cosewic.gc.ca), the sea otter was downlisted to threatened in 1996 and to special concern in 2007 by COSEWIC and the Species at Risk Act (SARA). Currently, the main threat is oil spills.

In Alaska, sea otters were severely depleted and locally extirpated along the main coast and on many of the Aleutian Islands. Here, the loss of sea otters caused outbreaks of sea urchins, one of their main prey species, which in turn consumed kelp forests, transforming them into urchin barrens (Figure I) [39,57]. The recovery of sea otters during the 20th century re-established the former trophic cascade and kelp forests recovered. However, since 1990, sea otters and kelp have decreased again, probably as a result of increased killer whale predation and oil spills, such as the Exxon Valdez [57,92].

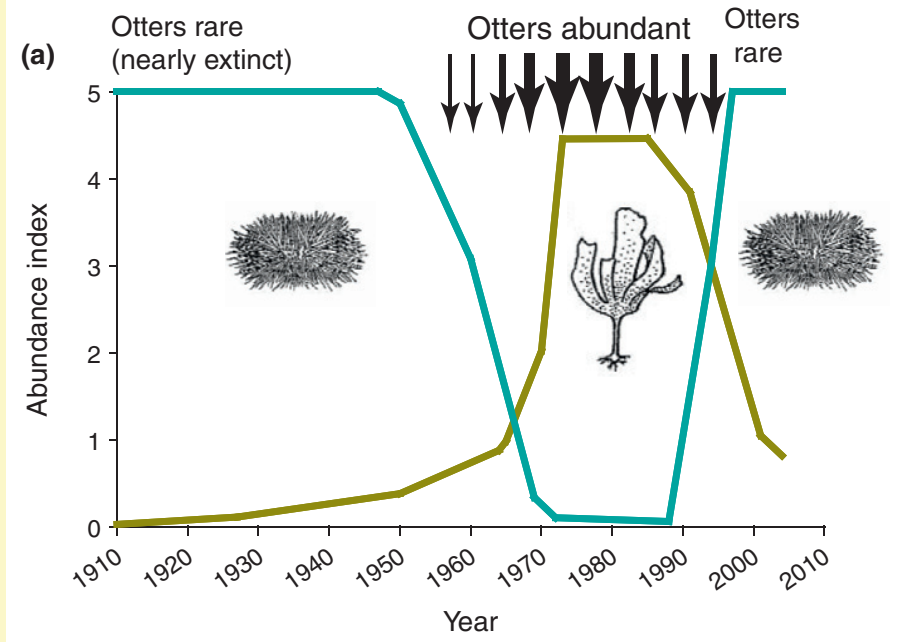

(b)

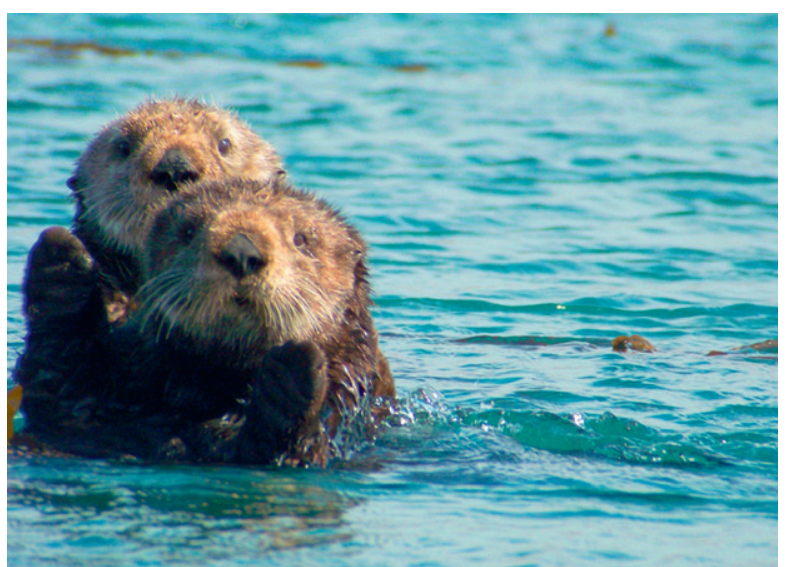

(d)

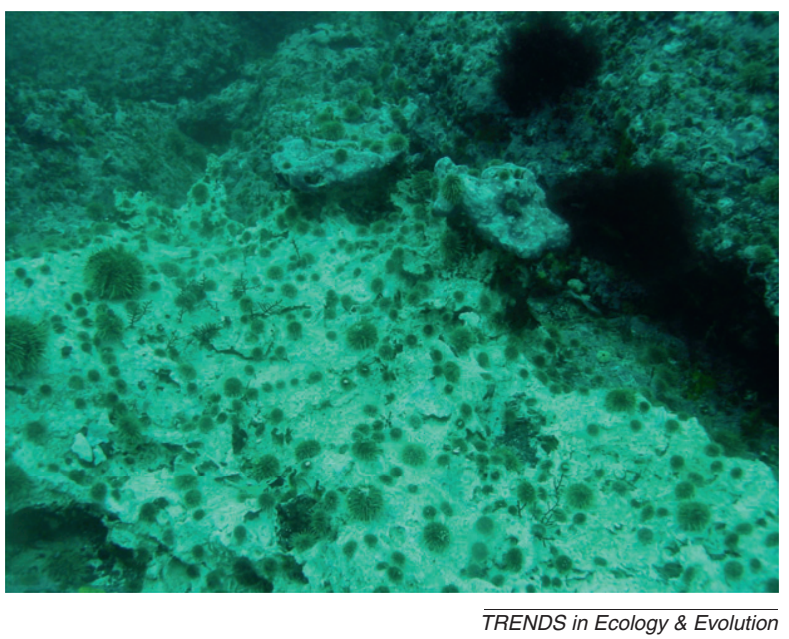

Figure I. Sea otter recovery. (a) Illustration of changes in the abundance of sea otters (arrows indicate the timing and magnitude of their role in changing the community), kelps (dark-yellow line) and sea urchins (blue line) in Amchitka, Alaska. Photographs of (b) sea otters in Morro Bay, California, (c) a kelp forest and (d) a sea urchin barren in the Aleutian Islands. Reproduced, with permission, from [57] (a); Madralynn Haye/Marine Photobank (b), Michael Kenner (c) and Robert Steneck (d). 


\section{Reptiles}

Over the past 25 years, six major green turtle Chelonia mydas nesting populations in Japan, Australia, Hawaii, Florida and Costa Rica have been increasing by $3.8-13.9 \%$ per year following protection from human exploitation of eggs and turtles (Figure 2c) [45]. Other sea turtle species have also shown some increases, although most are far from historical abundance levels and are listed as threatened or endangered $[40,45,46]$. By contrast, more offshoreventuring loggerhead Caretta caretta and leatherback Dermochelys coriacea turtles have experienced strong population declines owing to being bycatch in fisheries [47]. Other marine reptiles have also shown recovery, such as the American alligator Alligator mississippiensis in the southeast USA, owing to legal protection under the US Endangered Species Act and bans on hunting and trade [e.g. Convention on International Trade in Endangered Species (CITES) [40]].

\section{Fishes}

Over the past decade, stricter management and improved governance have enabled the rebuilding of some fish populations, whereas others remain at low population numbers $[8,9]$. After severe declines of groundfish stocks, a largescale fishing closure on Georges Bank in 1992 resulted in a strong increase of haddock Melanogrammus aeglefinus [8], whereas a fishing moratorium for cod Gadus morhua in Atlantic Canada after its collapse during the early 1990s has not yet resulted in significant recovery [20]. In the Southern California Bight, a ban of gill nets in 1994 resulted in the slow recovery of strongly depleted white sea bass Atractoscion nobilis and other predatory fishes (Figure 2d) [48]. Similarly, the ban of beach seine nets in combination with closed areas resulted in marked increases in fish abundance in Kenya [49]. In the Northwest Atlantic, profitability cessation of foreign fishing enabled the porbeagle shark Lamna nasus to recover after its stock collapsed during the $1960 \mathrm{~s}$, but renewed Canadian fisheries during the 1990s again depleted the population, until recent management measures halted its decline [50]. For diadromous fishes, recovery efforts often need to address multiple threats. Reduction of river pollution and creation of fish ladders on dams to access spawning habitat enabled strong returns of gaspereau Alosa spp. and Atlantic salmon Salmo salar in the St. Croix River, Canada during the 1980s before some dams were closed again in 1995 [42]. The recent removal of dams on the Kennebec River in Maine also resulted in strong returns of several diadromous fish species [51].

\section{Habitats}

Around the world, increasing efforts are directed towards the protection and restoration of coastal habitats, such as wetlands, mangroves, seagrass beds, kelp forests, and oyster and coral reefs. Some have achieved at least partial recovery, whereas others have not. For example, the reduction of nutrient pollution resulted in the recovery of $27 \mathrm{~km}^{2}$ of seagrass beds in Tampa Bay, Florida [52], 25 ha in Mumford Cove, Connecticut (Figure 3a) [53], and a more than threefold increase of seagrass beds up to $100 \mathrm{~km}^{2}$ in
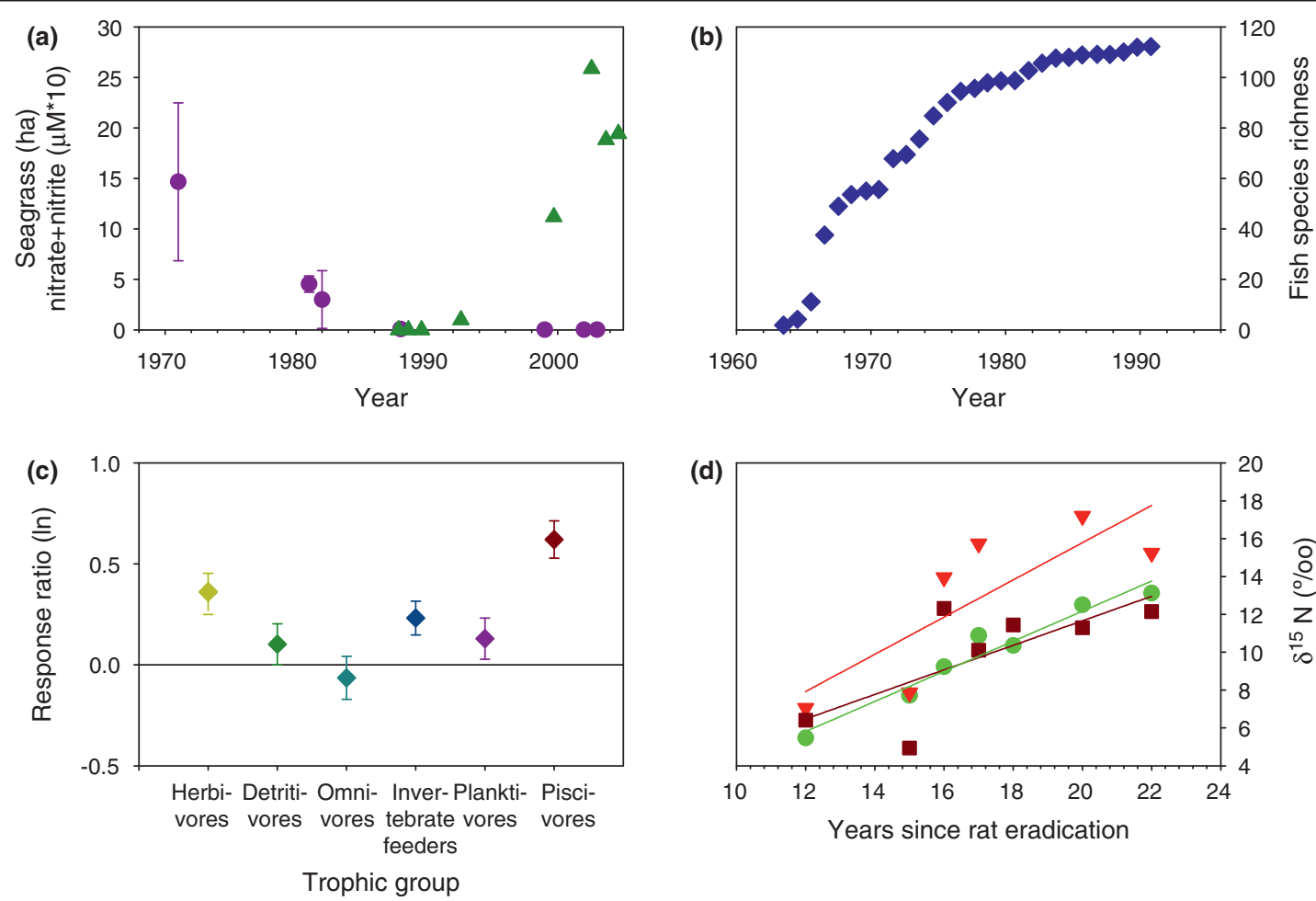

(d)

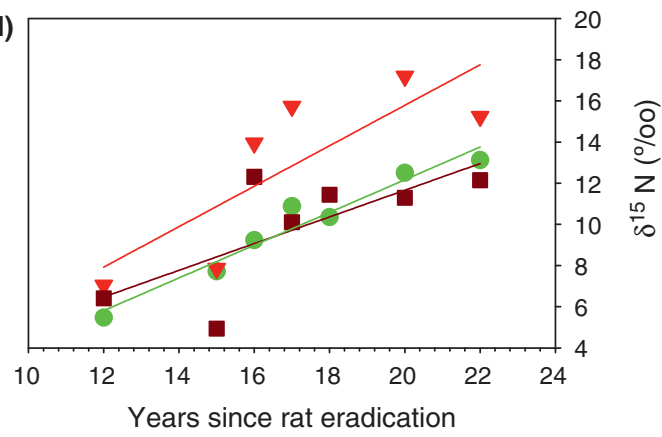

TRENDS in Ecology \& Evolution

Figure 3. Selected examples of ecosystem recovery: (a) Recovery of seagrass habitat (green triangles) after reduction of nutrient loading (nitrate and nitrite; purple circles) in Mumford Cove, Connecticut. (b) Cumulative increase in fish species richness after restoration of water quality in the Thames Estuary, UK. (c) Average increase (response ratio and $95 \% \mathrm{Cl}$ from a meta-analysis) in six trophic groups inside versus outside 31 marine protected areas. (d) Increase in marine-derived nitrogen $\left(\delta^{15} \mathrm{~N}\right.$, and linear regression lines) in terrestrial plants (green circles), spiders (red triangles) and soil (brown squares) provided by recovering seabird colonies after the eradication of rats on northeastern New Zealand islands. Reproduced, with permission, from [53] (a), [13] (b), [14] (c) and [17] (d). 
the Northfrisian Wadden Sea, Germany from 1994-2006 [54]. In Mondego Bay, Portugal, seagrass recovered from 0.02 to $1.6 \mathrm{~km}^{2}$ from 1997 to 2002 following management actions to restore water quality and estuarine circulation and to reduce disturbance from fishing practices [55].

Recovery can be more difficult when the former vegetation has been lost. In the Delmarva Coastal Bays, USA, eelgrass Zostera marina showed natural recovery after the 1930s wasting disease and hurricane destruction in the four northern bays, probably from small remnant stands [56]. By contrast, no recovery occurred in the southern bays, owing to seed limitation, before active restoration efforts. This is one of a few examples where restoration of lost seagrass beds has been successful [6]. On many temperate coasts, kelp forests have recovered from deforestation by sea urchins after sea urchin populations were reduced by natural predators (e.g. sea otters, Box 2), fishing or disease [57]. By contrast, where kelp forests have been replaced by algal turfs, sediments or mussel beds, recovery potential seems limited even when the proximate drivers of loss are removed [58,59], but assisted restoration can help [16].

For non-vegetated habitats, such as oyster and coral reefs, recovery has also been difficult $[60,61]$. However, the potential for recovery of native oyster reefs is emerging from restoration efforts at several key localities within Chesapeake Bay, Pamlico Sound, Strangford Lough in Northern Ireland and the Limfjord, Denmark [7]. Marine reserves can also help. Recovery of coral cover and size distribution after bleaching and hurricane disturbance was significantly enhanced inside a marine reserve in the Bahamas compared to outside, owing to higher abundance of herbivorous fishes and resulting lower macroalgal cover [62]. However, recovery might depend on the type, strength and timescale of the disturbance. Whereas some coral reefs might be able to recover from short-term bleaching and hurricane events within decades [63], recovery from long-term reef degradation might take centuries or longer $[2,64]$.

\section{Water quality}

Unregulated discharges of wastes and waste waters into rivers and estuaries have caused strong pollution problems, resulting in the decline or disappearance of many species, some of which have been successfully reversed $[40,42,65,66]$. For example, the implementation of pollution controls in the Thames estuary, UK during the 1960s enhanced water quality, especially oxygen levels, enabling the return of estuarine fishes (Figure 3b) [13]. A $10 \times$ reduction of nitrogen loads in Tampa Bay, Florida during the late 1970s led to decreasing cyanobacterial blooms, increasing water clarity and, 10 years later, the return of seagrasses [13,52]. Reduced nutrient loads also contributed to seagrass recovery in several other areas (Figure 3a) [53]. Water quality has also been restored with pollution controls in Galveston Bay and with the unintentional help of invasive clams in San Francisco Bay [40]. Long-term studies, however, show that sublethal effects and shifts in community structure can persist long after the recovery of target species abundance or ecosystem processes [65].

\section{Species diversity}

Although there are increasing numbers of examples of individual population recoveries, attempts and studies of recovery at a community or ecosystem level are scarce. However, some examples demonstrate the possibility of multi-species recoveries. Restoration of water quality resulted in the return of $>110$ fish species to the Thames estuary (Figure 3b) [13] and the recovery of intertidal macroalgal communities from 1984 to 2006 after implementing sewage treatment in Bilbao, Spain [66]. Cessation of exploitation in marine protected areas (MPAs) around the world resulted in significant increases in species richness of fishes and invertebrates [15,22] and habitat restoration of oyster reefs has enhanced associated species diversity [67].

\section{Ecosystem structure, functions and services}

In addition to species diversity, some studies have further demonstrated the recovery of structural or functional ecosystem components following protection measures. A large-scale fishing closure on Georges Bank during the 1990s enabled the recovery of the entire benthic community [9] and strongly reduced exploitation rates have led to the rebuilding of the fish community biomass in the California Current since 2000 [9]. Restoration of kelp along Korean coasts resulted in the complete recovery of macroalgal community structure and trophic food webs [16]. Studies in MPAs illustrate successional recovery of different community components (Figure 3c) as well as re-establishment of lost predatory interactions and food-web structure [14,15,68,69]. Moreover, significant increases occurred in secondary productivity, ecosystem stability and economic revenue from recreational diving in 48 MPAs and fisheries closures worldwide [22]. In Kenya, fishers' catches and income strongly increased after the establishment of closed areas combined with beach seine bans $[9,49]$. In some cases, marine recoveries can even benefit terrestrial ecosystems, as in the recovery of seabird colonies that enhance biodiversity and functions of island ecosystems by supplying essential marine-derived nitrogen (Figure 3d) [17]. Only a few marine ecosystems, such as Monterey Bay, California [70], have so far shown strong recovery in their structure, function and services over a large area.

\section{General patterns of recovery}

\section{How common is recovery?}

Despite an increasing number of case studies on marine recoveries, only a few have aimed at summarizing how common recovery is among a range of depleted populations or degraded ecosystems. A reconstruction of long-term trends in estuarine and coastal ecosystems revealed that only $14 \%$ of depleted species showed some recovery during the 20th century, mostly among birds, pinnipeds and sea otters, whereas others continued to decline or remained at low abundance [3]. A global review of historical baselines for large marine animals found that only 40 out of 256 depleted populations (15.6\%) experienced some recovery, 33 of them marine mammals [5]. A more detailed study on marine mammal recovery revealed that $35 \%$ of 88 distinct populations experienced significant population increases 
over three generations (Anna M. Magera, MSc thesis, Dalhousie University, 2011). Interestingly, recovery was more common among pinnipeds (50\%) than among cetaceans $(16 \%)$ and, within cetaceans, was more common in coastal $(32 \%)$ than offshore $(6 \%)$ populations. The lack of data on cryptic and offshore species might have resulted in an overestimation of recoveries in this study. In comparison, the International Union for the Conservation of Nature (IUCN) classified only $12 \%$ of all 127 marine mammal species as globally increasing, whereas the rest were decreasing, stable, or data deficient [12].

Among 1200 waterbird populations (out of 2305) with known trends, $17 \%$ were increasing compared with $40 \%$ that were decreasing in abundance [71]. The proportion of increasing species was larger in Europe and North America and lowest in Asia and Oceania. Globally, between 1994 and 2004, only $28 \%$ of all critically endangered birds benefited from conservation actions, with 24 species declining less severely and only 25 improving in status [72].

Among 232 fish stocks that experienced strong population declines, only $12 \%$ had fully recovered 15 years after collapse, whereas $40 \%$ showed no recovery [20]. Even among 74 USA fish stocks requiring recovery under the Magnuson-Stevens Act, only half showed some increase from 1996 to 2004 and just three (5\%) had reached their recovery target [8]. Across 166 assessed fish stocks worldwide, $63 \%$ had biomass levels below the traditional management target (biomass at maximum sustainable yield; $\mathrm{B}_{\mathrm{MSY}}$ ) and only $28 \%$ had reduced exploitation rates that would allow for rebuilding [9]. Moreover, although the average exploitation rate has been reduced in five out of ten large marine ecosystems, actual fish biomass has only begun to rebuild in three systems [9]. In a recent review of ecosystem recovery across 240 studies in terrestrial and aquatic systems, $37.5 \%$ showed recovery in some, and $34.5 \%$ in all variables measured [19]. In summary, it appears that recovery occurs in more than $10 \%$ but less than $50 \%$ of species or ecosystems, suggesting much need for improved management and conservation. Unfortunately, the overall conservation status of vertebrates worldwide is further declining, although the decline would be more severe without existing conservation successes [73]. Compared with terrestrial species, the Red List Index of marine mammals and birds is lower, but has been declining more rapidly over the past $10-20$ years [73].

\section{Magnitude of recovery}

Often the lack of historical baselines makes it difficult to assess the magnitude of recovery. However, some studies suggest that, although many species and habitats show some increase, only a few have so far rebounded to historical levels of abundance. Across 40 populations of large marine animals recovering from historical declines, average abundance increased from a low of $13 \%$ to $39 \%$ of historical levels, yet the magnitude of recovery strongly varied (from $2.3 \%$ to $96.5 \%$ ) among populations [5]. In estuaries and coastal seas, $12 \%$ of depleted species and habitats partially recovered to $>10 \%$ of former levels, whereas only $2 \%$ showed substantial increases to $>50 \%$ of their former abundance [3]. Among 47 marine mammal populations with historical reference points, recovery averaged $61 \%$ of former abundance, but with large variability from zero to $>100 \%$ (Anna M. Magera, MSc thesis, Dalhousie University, 2011). Interestingly, larger population declines were related to smaller recoveries. Similarly, fish stocks that experienced $>90 \%$ declines showed less recovery than those with $>70 \%$ decline, and only $12 \%$ fully recovered to former levels 15 years after their collapse [20]. Assessing quantitative recovery trends is not always easy and strongly depends on the amount and quality of available data, which are missing in the large proportion of species classified as data deficient by the IUCN [12] and for most marine habitats, including shallow ones [4]. Overall, however, the magnitude of recovery seems to depend on the time span, magnitude and type of disturbance among other factors, with higher depletion linked to lower recovery $[20,21]$.

\section{How long does recovery take?}

Long-lived marine animals might take many decades to recover from low population abundance owing to their slow life-history characteristics and low annual growth rates [45]. For example, many whales, seals, sea turtles and birds experienced several decades of low population numbers before signs of increase appeared [25,40,43,45]. Modeling efforts showed that North Atlantic porbeagle sharks probably require $70-100$ years to recover to their $\mathrm{B}_{\mathrm{MSY}}$ [50]. Documented finfish and invertebrate stock recovery times ranged from 3 to 30 years, with demersal recoveries generally being longer than pelagic ones [74]. Clupeids, such as herring and sardines, have shown more rapid recovery within 5-10 years after depletion, whereas gadoids showed no, or slow, recovery within 15 years after depletion [20]. In a MPA, species richness of coral reef fishes reached a plateau after 10 years, whereas density peaked after 7-37 years depending on the life history [15]. After benthic trawling, slower-growing sponges and corals took up to 8 years to recover compared with $<1$ years for polychaetes [21]. Yet, a deep seagrass meadow showed only a few signs of recovery 100 years after trawling [75], and a megabenthic seamount assemblage failed to recover 5-10 years after trawling [76]. Population or ecosystem recovery might take even longer if there has been a regime shift, as in the Benguela ecosystem [18].

In a recent review, the average recovery time for different ecosystems types ranged from 10 to 42 years, with slowsuccessional ecosystems taking longer than short-lived ones [19]. When considering different perturbation types, average recovery time ranged from 20 years to $>56$ years when multiple interacting perturbations were involved, and recovery from human disturbances took longer than from natural disturbances, such as hurricanes or cyclones [19].

Once lost or abandoned, natural recolonization of former habitats might take much longer than recovery from remnant but still existing local populations. For example, recolonization of former breeding colonies in the Bay of Fundy occurred only after an average of $70( \pm 12)$ years, with 45 years for the common murre Uria aalge and 133 years for the Northern gannet Morus bassanus [42]. In the Wadden Sea, at least three bird species and grey seals Halichoerus grypus re-established breeding colonies after 
Table 1. Direct management and conservation actions that have helped population or ecosystem recoveries

\begin{tabular}{|l|l|}
\hline Management and conservation action & Refs \\
\hline Reduced or banned exploitation & {$[25,42]$} \\
\hline Commercial whaling & {$[42]$} \\
\hline Seal hunting and bounty hunting & {$[3,40,43]$} \\
\hline Bird hunting and egg collection & {$[45]$} \\
\hline Turtle hunting and egg collection & {$[8,9]$} \\
\hline Fishing pressure & {$[48]$} \\
\hline Altering exploitation measures (more selective, less destructive) \\
\hline Ban of gill nets & {$[9,49]$} \\
\hline Ban of beach seines & {$[40,45]$} \\
\hline Reduced bycatch & \\
\hline Habitat protection & {$[7,14,15,22$,} \\
\hline MPAs & $62,68-70]$ \\
\hline Breeding colonies & {$[40-43,94]$} \\
\hline Habitat restoration & \\
\hline Seagrass seeding, transplants & {$[6,56]$} \\
\hline Kelp restoration & {$[16]$} \\
\hline Constructed oyster reefs & {$[95]$} \\
\hline Dam removal in rivers & {$[42,51]$} \\
\hline Pollution control & \\
\hline Ban of DDT (e.g. recovery of eagles and osprey) & {$[40]$} \\
\hline River pollution control & {$[13,42]$} \\
\hline (e.g. return of fishes) & {$[6,13,52,53,55]$} \\
\hline Reduced nutrient loading & \\
\hline (e.g. seagrass recovery) & \\
\hline Re-introduction & {$[42]$} \\
\hline Peregrine falcon, Atlantic Canada & {$[33,92]$} \\
\hline Sea otter, British Columbia & {$[3,83,85]$} \\
\hline Addressing cumulative effects & \\
\hline &
\end{tabular}

more than 5 centuries of absence [43]. Recovery of eelgrass beds after the 1930s wasting disease took decades in some areas, whereas other areas remain unvegetated [54,56]. Thus, even if all threats are reduced, recovery might still take decades to centuries for long-lived species, habitats and complex ecosystems, and clearly depends not only on the life-history characteristics of the species and the succession rate of the ecosystems, but also on the type and magnitude of disturbance.

\section{Drivers of recovery}

What has helped?

The most obvious drivers of recovery are the reduction of those human impacts that caused the depletion or degradation in the first place (Table 1). For example, banning or reducing commercial exploitation and protecting breeding habitats have helped many marine mammals, birds and sea turtles to increase in number (Box 2) [3,25]. Reduced exploitation rates or implementation of more selective and less destructive fishing gears has enabled the recovery of many fish populations $[8,9,48,49]$. Pollution controls and habitat restoration have had important roles in the recovery of diadromous fishes [13,42,51].

Overall, in terms of relative importance of the different factors, it has been shown that $95 \%$ of recoveries of exploited marine species in estuarine and coastal regions were enabled by reduced or banned exploitation; $72 \%$ by habitat protection, especially of breeding colonies and
Table 2. Other societal and ecological factors that are needed for recovery

\begin{tabular}{|c|c|}
\hline Societal and ecological factors & Refs \\
\hline \multicolumn{2}{|l|}{ Awareness } \\
\hline Fashion ideas have changed (e.g. bird feathers) & {$[40,77]$} \\
\hline Animal ethics have changed (e.g. whaling) & [40] \\
\hline Recognition of problems (e.g. oyster reefs) & [7] \\
\hline Conservation awareness (e.g. IUCN Red List) & {$[12,73]$} \\
\hline \multicolumn{2}{|l|}{ Economic forces } \\
\hline Changes in economic viability of exploitation & [78] \\
\hline $\begin{array}{l}\text { Alternative products (e.g. mineral oil replacing } \\
\text { marine mammal oil) }\end{array}$ & {$[40,42]$} \\
\hline \multicolumn{2}{|l|}{ Legal protection } \\
\hline $\begin{array}{l}\text { Endangered species legislation (e.g. ESA in } \\
\text { USA or SARA in Canada) }\end{array}$ & {$[38,40,92]$} \\
\hline Trade bans (e.g. Lacey Act in USA and CITES) & {$[40]$} \\
\hline $\begin{array}{l}\text { Exploitation bans (e.g. Whaling Moratorium, } \\
\text { Fur Seal Treaty and Migratory Bird Act) }\end{array}$ & {$[40,92]$} \\
\hline $\begin{array}{l}\text { Habitat protection (e.g. Habitat Directive } \\
\text { and Ramsar Convention) }\end{array}$ & {$[4,7,40]$} \\
\hline \multicolumn{2}{|c|}{ Enforcement of management and conservation plans } \\
\hline Reduced fishing pressure & {$[8,9]$} \\
\hline Control of unregulated and illegal harvest & {$[9,79]$} \\
\hline \multicolumn{2}{|l|}{ Community involvement and governance } \\
\hline $\begin{array}{l}\text { Community-based management } \\
\text { (e.g. Kenya, Chile and Mexico) }\end{array}$ & {$[9,49,80]$} \\
\hline \multicolumn{2}{|l|}{ Population factors } \\
\hline Life history (time to rebound) & {$[20,21,42,50,85]$} \\
\hline Magnitude of depletion and Allee effects & [20] \\
\hline Habitat range and occupancy & {$[47,83]$} \\
\hline $\begin{array}{l}\text { Population structure (e.g. juvenile:adult, } \\
\text { male:female and meta-population) }\end{array}$ & {$[91,94]$} \\
\hline \multicolumn{2}{|l|}{ Diversity } \\
\hline Genetic diversity & {$[81,96]$} \\
\hline Species richness & [22] \\
\hline \multicolumn{2}{|l|}{ Ecosystem health } \\
\hline Water quality & [13] \\
\hline Habitat availability & {$[42,43,59]$} \\
\hline Species interactions & {$[28,57,58,68,69]$} \\
\hline Primary production & [23] \\
\hline Climate & [97] \\
\hline
\end{tabular}

feeding grounds; and $8 \%$ by pollution controls $[3,40]$. In most cases $(78 \%)$, these measures were most successful when implemented in combination. For locally extirpated species, assisted re-introduction has enabled some successful re-establishments of wild populations [38,42].

\section{What else is needed?}

To enable recoveries, some further societal and ecological factors need to be considered (Table 2). One first step is awareness on all levels of society. This ranges from general shifts in cultural values (e.g. fashion ideals or animal ethics), which contributed to the rise of wild species conservation during the 19 th and 20 th centuries $[40,77]$, to public and community support for conservation actions and political willingness to implement meaningful management plans [7,9]. Shifts in economic forces also contributed to recovery. For example, decreased economic viability of targeting depleted stocks and introduction of alternative products, such as mineral oil replacing whale oil, probably spared decimated populations further 
declines [40,42,78]. In many cases, legal protection (e.g. endangered species legislation or trade bans) was essential for recovery (Box 2, Table 2) [40]. Moreover, stringent enforcement of management plans was often necessary, including actual reduction of excessive fishing pressure to the advised management target ( $\mathrm{F}_{\mathrm{MSY}}$ ) and control of unregulated or illegal harvests [8,9,79]. Involvement of local communities was essential for promoting management and conservation actions in other cases $[9,80]$.

Aside from direct management measures, recovery might also depend on population-level factors (Table 2). The magnitude of previous population depletion, population and meta-population structure, genetic diversity and life-history characteristics have all been shown to be important determinants of recovery [20,81] (Anna M. Magera, MSc thesis, Dalhousie University, 2011). Long-lived marine animals have lower intrinsic rates of increase and will take longer to rebound to higher abundance levels than will short-lived species [20,21]. Yet, charismatic and easily visible species might profit from enhanced public awareness and protection (Anna M. Magera, MSc thesis, Dalhousie University, 2011). At low abundance levels, populations might not be viable and head towards inevitable decline owing to Allee effects. Here, natural or humanaided re-introduction or translocation can support recovery of extirpated or suppressed populations (Box 2) [7,42]. Integrity of social structure and culture might also be important [82]. The habitat and range of occurrence of a species might also have a role. Recovering species often occupy a greater percentage of their historic range compared with non-recovering species [83], and more coastal marine mammals and sea turtles have shown more recovery than have offshore species, which face continued threats and less management [47] (Anna M. Magera, MSc thesis, Dalhousie University, 2011). Also, recoveries are most common in more developed regions, such as Europe and North America, where conservation efforts have often started earlier and are more intense [9,71].

Finally, community or ecosystem-level factors might be important in determining recovery (Table 2). Most species require sufficient water quality, food and habitat, and are part of an intricate net of species interactions, including predator-prey interactions, competition and facilitation, that are needed to function and thrive [42]. Thus, species diversity has been positively correlated to recovery, for example in fish stocks [22]. However, altered species interactions can go both ways. Recovery potential seems lower whenever strong competitors inhabit the niche previously occupied by the depleted or lost habitat or species [58,84]. By contrast, the strong decline in large predatory sharks might have positively contributed to recent recoveries of many marine vertebrates, for which they are often a major or sole predator [28]. Changes in ecosystem productivity or environmental conditions have also been shown to influence recovery $[23,85]$. Restoring the environmental conditions to those before the collapse of a species might also be necessary, but not sufficient for recovery [86].

All the abovementioned natural and anthropogenic factors, of course, do not act in isolation. The reduction of cumulative human impacts was important in $78 \%$ of historical recoveries [3]. Compared with non-recovering species, recovering endangered species occupy a greater percentage of their historic range, face threats that are easier to address and have a greater percentage of their recovery management objectives completed [83]. In addition, the four best additive predictors of successful fish stock recovery were the rapid reduction in fishing mortality, environmental conditions during the recovery period, life-history characteristics of the target stock and management performance criteria [85]. Thus, overall, the reduction of human impacts and protection of species clearly helps, but favorable ecological and environmental conditions are also necessary to aid recovery.

\section{Concluding remarks}

Overall, our review shows that recovery of depleted marine populations, habitats and ecosystems is possible. This could provide a promising outlook on the future of marine biodiversity and ocean ecosystems. However, the proportion and magnitude of recoveries so far is not enough to halt the overall decline in marine species and ecosystems $[3,12,73]$. As advice for current and future management and conservation, our review shows that recovery needs a concerted, sustained and properly enforced effort. The best strategies for recovery include: (i) raising public and political awareness; (ii) taking legal action and enforcing management plans; (iii) addressing cumulative human impacts; (iv) maintaining or restoring biodiversity and ecosystem complexity; and (v) planning for the long term, as recovery of long-lived species and complex ecosystems might need decades, if not centuries after major threats have been removed or reduced. These lessons learned from past recoveries of many marine mammals, birds, reptiles, some fishes and habitats could be applied to species that are currently undergoing strong population declines but have received little protection so far, such as many sharks $[28,50,87]$, and to species that are increasingly exploited with little management in place, such as many invertebrates [88]. Whereas much trial and error was previously involved in finding the right management and conservation actions, current and future recovery plans could be better informed and take hold before populations or habitats reach critically low levels.

Our review also indicates that there is still much to learn about marine recoveries. Many studies suggest the importance of multiple interacting forces in driving recovery, such as the reduction of cumulative human impacts or any combination of reduced threats with favorable environmental, ecological, social or economic factors $[3,83,85]$. Future research should aim to identify and quantify which combination of factors is most crucial for the recovery of depleted populations and degraded ecosystems to make conservation and management strategies most cost effective. Future studies should also address how regime shifts and alternative stable states affect recovery prospects $[18,86]$. Moreover, identifying historical reference points and carrying capacity for individual populations and ecosystems is key for setting conservation and management targets. Here, crucial knowledge gaps exist in how changes in ecosystems or environmental conditions over time have altered such baselines and, hence, recovery prospects. There is also a lack of research on the recovery of currently 
threatened (e.g. sharks) or highly exploited (e.g. invertebrates) species. Finally, it is not just the responsibility of conservation and management agencies to conduct the right actions to enable recovery. Each individual, and society as a whole, can influence the depletion and recovery of marine species and ecosystems. Research on the effects of shifts in awareness, cultural values, consumer demand and economic forces could greatly contribute to making marine recoveries a more common success story.

\section{Acknowledgments}

We are grateful to B. Worm, F. Ferretti, M.W. Beck and many colleagues for inspiring discussions and critical comments on this subject. Financial support was provided by the Sloan Foundation's Census of Marine Life FMAP Program, the Natural Sciences and Engineering Research Council of Canada and Dalhousie University. MC was funded by the European Community Marie-Curie Post-doctoral Fellowship through the International Outgoing Fellowships (IOF; Call: FP7-PEOPLE-2007-4-1IOF) to ECOFUN and LA by the European Commission through FP7.2009-1, Contract 244104-THESEUS.

\section{References}

1 Jackson, J.B.C. et al. (2001) Historical overfishing and the recent collapse of coastal ecosystems. Science 293, 629-638

2 Pandolfi, J.M. et al. (2003) Global trajectories of the long-term decline of coral reef ecosystems. Science 301, 955-958

3 Lotze, H.K. et al. (2006) Depletion, degradation, and recovery potential of estuaries and coastal seas. Science 312, 1806-1809

4 Airoldi, L. and Beck, M.W. (2007) Loss, status, and trends for coastal marine habitats of Europe. Oceanogr. Mar. Biol. Annu. Rev. 45, 345405

5 Lotze, H.K. and Worm, B. (2009) Historical baselines for large marine animals. Trends Ecol. Evol. 24, 254-262

6 Waycott, M. et al. (2009) Accelerating loss of seagrasses across the globe threatens coastal ecosystems. Proc. Natl. Acad. Sci. U.S.A. 106, 1237712381

7 Beck, M.W. et al. (2011) Oyster reefs at risk and recommendations for conservation, restoration, and management. BioScience 61, 107-116

8 Rosenberg, A.A. et al. (2006) Rebuilding US fisheries: progress and problems. Front. Ecol. Environ. 4, 303-308

9 Worm, B. et al. (2009) Rebuilding global fisheries. Science 325, 578-585

10 Dulvy, N.K. et al. (2003) Extinction vulnerability in marine populations. Fish Fish. 4, 25-64

11 Myers, R.A. and Worm, B. (2005) Extinction, survival or recovery of large predatory fishes. Philos. Trans. R. Soc. Lond. B 360, 13-20

12 Vié, J-C. et al. (2009) Wildlife in a Changing World - An Analysis of the 2008 IUCN Red List of Threatened Species, IUCN

13 Cloern, J.E. (2001) Our evolving conceptual model of the coastal eutrophication problem. Mar. Ecol. Prog. Ser. 210, 223-253

14 Micheli, F. et al. (2004) Trajectories and correlates of community change in no-take marine reserves. Ecol. Appl. 14, 1709-1723

15 McClanahan, T.R. et al. (2007) Toward pristine biomass: reef fish recovery in coral reef marine protected areas in Kenya. Ecol. Appl. 17, 1055-1067

16 Kang, C. et al. (2008) Food web structure of a restored macroalgal bed in the eastern Korean peninsula determined by $\mathrm{C}$ and $\mathrm{N}$ stable isotope analyses. Mar. Biol. 153, 1181-1198

17 Jones, H.P. (2010) Seabird islands take mere decades to recover following rat eradication. Ecol. Appl. 20, 2075-2080

18 Van der Lingen, C.D. et al. (2006) Resource and ecosystem variability, including regime shifts, in the Benguela current system. In Benguela: Predicting a Large Marine Ecosystem. Part II, Chapter 8 (Shannon, L.V. et al., eds), pp. 147-184, Large Marine Ecosystem Series, Elsevier

19 Jones, H.P. and Schmitz, O.J. (2009) Rapid recovery of damaged ecosystems. PLoS ONE 4, e5653

20 Hutchings, J.A. and Reynolds, J.D. (2004) Marine fish population collapses: consequences for recovery and extinction risk. BioScience 54, 297-309

21 Kaiser, M.J. et al. (2006) Global analysis of response and recovery of benthic biota to fishing. Mar. Ecol. Prog. Ser. 311, 1-14
22 Worm, B. et al. (2006) Impacts of biodiversity loss on ocean ecosystem services. Science $314,787-790$

23 Duarte, C.M. et al. (2009) Return to neverland: shifting baselines affect eutrophication restoration targets. Est. Coasts 32, 29-36

24 Redford, K.H. et al. (2011) What does it mean to successfully conserve a (vertebrate) species? BioScience 61, 39-48

25 Baker, C.S. and Clapham, P.J. (2004) Modelling the past and future of whales and whaling. Trends Ecol. Evol. 19, 365-371

26 Rose, G.A. (2004) Reconciling overfishing and climate change with stock dynamics of Atlantic cod (Gadus morhua) over 500 years. Can. J. Fish. Aquat. Sci. 61, 1553-1557

27 Fromentin, J-M. (2009) Lessons from the past: investigating historical data from bluefin tuna fisheries. Fish Fish. 10, 197-216

28 Ferretti, F. et al. (2010) Patterns and ecosystem consequences of shark declines in the ocean. Ecol. Lett. 13, 1055-1071

29 Hughes, T.P. et al. (2005) New paradigms for supporting the resilience of marine ecosystems. Trends Ecol. Evol. 20, 380-386

30 Palumbi, S.R. et al. (2008) Ecosystems in action: lessons from marine ecology about recovery, resistance, and reversibility. BioScience 58, $33-42$

31 Gunderson, L. et al. (2010) Foundations of Ecological Resilience, Island Press

32 Sanderson, E.W. (2006) How many animals do we want to save? The many ways of setting population target levels for conservation. BioScience 56, 911-922

33 Alter, S.E. et al. (2007) DNA evidence for historic population size and past ecosystem impacts of gray whales. Proc. Natl. Acad. Sci. U.S.A. 104, 15162-15167

34 Gerber, L.R. et al. (2007) Ten thousand and increasing: is the western Arctic population of bowhead whale endangered? Biol. Cons. 137, $577-583$

35 Whitehead, H. (2002) Estimates of the current global population size and historical trajectory for sperm whales. Mar. Ecol. Prog. Ser. 242, 295-304

36 Branch, T.A. et al. (2004) Evidence for increases in Antarctic blue whales based on Bayesian modelling. Mar. Mam. Sci. 20, 726-754

37 Carretta, J.V. et al. (2005) U. S. Pacific marine mammal stock assessments: 2004. NOAA Tech. Mem. NMFS-SWFSC-375 1-316

38 Gregr, E.J. et al. (2008) Estimating carrying capacity for sea otters in British Columbia. J. Wildl. Manag. 72, 382-388

39 Estes, J. et al. (2010) Using ecological function to develop recovery criteria for depleted species: sea otters and kelp forests in the Aleutian archipelago. Cons. Biol. 24, 852-860

40 Lotze, H.K. (2010) Historical reconstruction of human-induced changes in U.S. estuaries. Oceanogr. Mar. Biol. Annu. Rev. 48, 267-338

41 Oro, D. and Ruxton, G.D. (2001) The formation and growth of seabird colonies: Audouin's gull as a case study. J. Anim. Ecol. 70, 527-535

42 Lotze, H.K. and Milewski, I. (2004) Two centuries of multiple human impacts and successive changes in a North Atlantic food web. Ecol. Appl. 14, 1428-1447

43 Lotze, H.K. (2005) Radical changes in the Wadden Sea fauna and flora over the last 2000 years. Helgol. Mar. Res. 59, 71-83

44 Jones, H.P. (2010) Prognosis for ecosystem recovery following rodent eradication and seabird restoration in an island archipelago. Ecol. Appl. 20, 1204-1216

45 Chaloupka, M. et al. (2008) Encouraging outlook for recovery of a once severely exploited marine megaherbivore. Global Ecol. Biogeogr. 17, 297-304

46 McClenachan, L. et al. (2006) Conservation implications of historic sea turtle nesting beach loss. Front. Ecol. Environ. 4, 290-296

47 Lewison, R.L. et al. (2004) Quantifying the effects of fisheries on threatened species: the impact of pelagic longlines on loggerhead and leatherback sea turtles. Ecol. Lett. 7, 221-231

48 Pondella, D.J. and Allen, L.G. (2008) The decline and recovery of four predatory fishes from the Southern California Bight. Mar. Biol. 154, 307-313

49 McClanahan, T.R. et al. (2008) Malthusian overfishing and efforts to overcome it on Kenyan coral reefs. Ecol. Appl. 18, 1516-1529

50 Dulvy, N.K. et al. (2008) You can swim but you can't hide: the global status and conservation of oceanic pelagic sharks and rays. Aquat. Cons. Mar. Freshw. Ecosyst. 18, 459-482

51 Cane, J. (2009) 'Setting the river free': the removal of the Edwards dam and the restoration of the Kennebec River. Wat. Hist. 1, 131-148 
52 Greening, H. and Janicki, A. (2006) Toward reversal of eutrophic conditions in a subtropical estuary: water quality and seagrass response to nitrogen loading reductions in Tampa Bay, Florida USA. Environ. Manag. 38, 163-178

53 Vaudrey, J.M.P. et al. (2010) Eelgrass recovery after nutrient enrichment reversal. Aquat. Bot. 93, 237-243

54 Reise, K. and Joern, K. (2008) Seagrass recovery in the northern Wadden Sea? Helgol. Mar. Res. 62, 77-84

55 Cardoso, P. et al. (2010) Implications of nutrient decline in the seagrass ecosystem success. Mar. Poll. Bull. 60, 601-608

56 Orth, R. et al. (2006) Seagrass recovery in the Delmarva Coastal Bays, USA. Aquat. Bot. 84, 26-36

57 Steneck, R.S. et al. (2002) Kelp forest ecosystems: biodiversity, stability, resilience and future. Environ. Cons. 29, 436-459

58 Gorman, D. and Connell, S. (2009) Recovering subtidal forests in human-dominated landscapes. J. Appl. Ecol. 46, 1258-1265

59 Perkol-Finkel, S. and Airoldi, L. (2010) Loss and recovery potential of marine habitats: an experimental study of factors maintaining resilience in subtidal algal forests at the Adriatic Sea. PLoS ONE 5, e10791

60 Rogers, C.S. and Miller, J. (2006) Permanent 'phase shifts' or reversible declines in coral cover? Lack of recovery of two coral reefs in St. John, US Virgin Islands. Mar. Ecol. Prog. Ser. 306, 103-114

61 Baker, A.C. et al. (2008) Climate change and coral reef bleaching: an ecological assessment of long-term impacts, recovery trends and future outlook. Est. Coast. Shelf Sci. 80, 435-471

62 Mumby, P.J. and Harborne, A.R. (2010) Marine reserves enhance the recovery of corals on Caribbean reefs. PLoS ONE 5, e8657

63 Adjeroud, M. et al. (2009) Recurrent disturbances, recovery trajectories, and resilience of coral assemblages on a South Central Pacific reef. Coral Reefs 28, 775-780

64 Pandolfi, J.M. and Jackson, J.B.C. (2006) Ecological persistence interrupted in Caribbean coral reefs. Ecol. Lett. 9, 818-826

65 Hawkins, S. et al. (2002) Recovery of polluted ecosystems: the case for long-term studies. Mar. Environ. Res. 54, 215-222

66 Díez, I. et al. (2009) Recovery stages over long-term monitoring of the intertidal vegetation in the 'Abra de Bilbao' area and on the adjacent coast (N. Spain). Eur. J. Phycol. 44, 1-14

67 Coen, L. et al. (2007) Ecosystem services related to oyster restoration. Mar. Ecol. Prog. Ser. 341, 303-307

68 Guidetti, P. and Sala, E. (2007) Community-wide effects of marine reserves in the Mediterranean Sea. Mar. Ecol. Prog. Ser. 335, 43-56

69 Libralato, S. et al. (2010) Food-web traits of protected and exploited areas of the Adriatic Sea. Biol. Cons. 143, 2182-2194

70 Palumbi, S.R. and Sotka, C. (2010) The Death and Life of Monterey Bay: A Story of Revival, Island Press

71 Delany, S. and Scott, D. (2006) Waterbird Population Estimates, Wetlands International

72 Brooke, M.d.L. et al. (2008) Rates of movement of threatened bird species between IUCN Red List categories and toward extinction. Cons. Biol. 22, 417-427

73 Hoffmann, M. et al. (2010) The impact of conservation on the status of the world's vertebrates. Science 330, 1503-1509

74 Caddy, J.F. and Agnew, D.J. (2004) An overview of recent global experience with recovery plans for depleted marine resources and suggested guidelines for recovery planning. Rev. Fish Biol. Fish. 14, $43-112$
75 Gonzalez-Correa, J.M. et al. (2005) Recovery of deep Posidonia oceanica meadows degraded by trawling. J. Exp. Mar. Biol. Ecol. 320, 65-76

76 Williams, A. et al. (2010) Seamount megabenthic assemblages fail to recover from trawling impacts. Mar. Ecol. Evol. Persp. 31, 183-199

77 Forbes, L. and Jermier, J. (2002) The institutionalization of bird protection: Mabel Osgood Wright and the early Audubon movement. Organ. Environ. 15, 458-465

78 Schneider, V. and Pearce, D. (2004) What saved the whales? An economic analysis of 20th century whaling. Biodiv. Cons. 13, 543-562

79 Smyth, D. et al. (2009) Impacts of unregulated harvesting on a recovering stock of native oysters (Ostrea edulis). Mar. Poll. Bull. 58, 916-922

80 Defeo, O. and Castilla, J.C. (2005) More than one bag for the world fishery crisis and keys for co-management successes in selected artisanal Latin American shellfisheries. Rev. Fish Biol. Fish. 15, 265-283

81 Hughes, A. and Stachowicz, J. (2011) Seagrass genotypic diversity increases disturbance response via complementarity and dominance. J. Ecol. 99, 445-453

82 Whitehead, H. (2010) Conserving and managing animals that learn socially and share cultures. Learn. Behav. 38, 329-336

83 Abbitt, R.J.F. and Scott, J.M. (2001) Examining differences between recovered and declining endangered species. Cons. Biol. 15, 1274-1284

84 Lindegren, M. et al. (2010) Regime shifts, resilience and recovery of a cod stock. Mar. Ecol. Prog. Ser. 402, 239-253

85 Hammer, C. et al. (2010) Framework of stock-recovery strategies: analyses of factors affecting success and failure. ICES J. Mar. Sci. 67, 1849-1855

86 Scheffer, M. et al. (2001) Catastrophic shifts in ecosystems. Nature 413, 591-596

87 Ward-Paige, C. et al. (2010) Large-scale absence of sharks on reefs in the greater-Caribbean: a footprint of human pressures. PLoS ONE 5, e11968

88 Anderson, S.C. et al. (2011) Rapid global expansion of invertebrate fisheries: trends, drivers, and ecosystem effects. PLoS ONE 6, e14735

89 Gerrodette, T. and Demaster, D.P. (1990) Quantitative determination of optimum sustainable population level. Mar. Mam. Sci. 6, 1-16

90 DFO (2003) Atlantic Seal Hunt Management Plan 2003-2005, Fisheries and Oceans, (Canada)

91 Gerber, L.R. and Heppell, S.S. (2004) The use of demographic sensitivity analysis in marine species conservation planning. Biol. Cons. 120, 121-128

92 U.S. Fish and Wildlife Service (2010) Southwest Alaska Distinct Population Segment of the Northern Sea Otter (Enhydra lutris kenyoni) - Draft Recovery Plan, US Fish and Wildlife Service

93 U.S. Fish and Wildlife Service (2003) Final Revised Recovery Plan for the Southern Sea Otter (Enhydra lutris nereis), US Fish and Wildlife Service

94 Oro, D. (2003) Managing seabird metapopulations in the Mediterranean: constraints and challenges. Scientia Mar. 67, 13-22

95 Powers, S. et al. (2009) Success of constructed oyster reefs in no-harvest sanctuaries: implications for restoration. Mar. Ecol. Prog. Ser. 389, $159-170$

96 Reusch, T.B.H. et al. (2005) Ecosystem recovery after climatic extremes enhanced by genotypic diversity. Proc. Natl. Acad. Sci. U.S.A. 102, $2826-2831$

97 Frank, K.T. et al. (2007) The ups and downs of trophic control in continental shelf ecosystems. Trends Ecol. Evol. 22, 236-242 